innovative treatments, such as therapies that modify the immune response. "All of these incentives rely on the same types of molecules we've been using for 70 years," he says. Dalbavancin and oritavancin are designed to address the issue of methicillinresistant $S$. aureus (MRSA). In phase 3 trials, $20-30 \%$ of the enrolled patients were MRSA positive and responded as well as those patients with methicillin-sensitive $S$. aureus infections.

Noninferiority trials, such as the one done for dalbavancin, are designed to show that a new drug is no worse than an old drug. Powers is concerned that the QIDP designation may endow noninferior drugs with a false image of superiority that could lead to overuse. Furthermore, the GAIN Act does not include any stewardship mandate to manage the usage of new antimicrobials. So although the arsenal of antimicrobials will grow, Powers says, "your arsenal will be shooting blanks in the next ten years."

Logistics and risk deter companies from conducting focused studies on cohorts of patients with antibiotic-resistant infections.
The Antibiotic Development to Advance Patient Treatment (ADAPT) Act of 2013 would lower the standards for sample size and trial length for antimicrobials to treat serious infections through the Limited Population Antibacterial Drug pathway. Supporters of the ADAPT Act, like the IDSA, hope it will encourage pharmaceutical companies to conduct trials using patients with serious resistant infections and no options-those who need the drugs the most.

Amanda B Keener

\title{
Transmission catalog proposed to help combat zoonotic diseases
}

BOSTON - Two years ago, after returning home to the University of WisconsinMadison from a research trip in the forests of equatorial Africa, Tony Goldberg discovered an unwanted souvenir. There was a tick, the size of a pencil eraser, nestled inside his right nostril.

Goldberg carefully removed the specimen and, like any good scientist, proceeded to analyze the tick's DNA and morphology. The genetic similarity the insect showed with those found on chimpanzees from his field site in Uganda's Kibale National Park-as well as the appearance of such ticks in up-close images of these animals' noses-led Goldberg to believe that his nasal invader was probably an uncharacterized species that had adapted to living in chimp nostrils as a defense against grooming ${ }^{1}$. Perhaps more importantly, the fact that the tick had successfully infested a person's nose canal-his own-meant that Goldberg had inadvertently documented a potential new route of zoonotic pathogen transmission to humans.

Goldberg didn't suffer any ill effects from the tick. But the discovery got him thinking: how many more novel zoonotic infection routes remain undescribed for pathogens that pose a potential human health risk?

Seeking answers, Goldberg is now calling for a systematic effort on the part of disease ecologists, epidemiologists and social scientists to understand all the ways by which diseases might find their way from nature into human hosts. "The discovery of so many new and exciting pathogens will be most useful for public health if such pathogen discovery is complemented by a concomitant increase in our understanding of the many transmission pathways," Goldberg told Nature Medicine. He presented his vision here on 20 May at the American Society for Microbiology general meeting.

Many experts in the field are rallying behind Goldberg's call to action. "We know very little about the mechanics of transmission in many cases," says Simon Frost, a mathematical biologist who studies the dynamics of infectious diseases at the University of Cambridge, UK. "By understanding the various ways that we can contact [disease] reservoirs, and also how that changes over time, that helps us to anticipate new emerging infectious diseases."

\section{Beyond bushmeat}

Approximately three-quarters of emerging infectious diseases in humans arise by crossspecies transfer ${ }^{2}$. One of the most famous examples of such a zoonotic pathogen is HIV, which is thought to have spread to humans after hunters and butchers in Africa came into contact with the meat of primates infected with SIV, a closely related simian virus. However, monkeys and apes are only one potential reservoir for new human diseases. Just last month, for example, scientists pinpointed camels as the direct source of the virus responsible for Middle East respiratory syndrome $e^{3,4}$, a new disease that has claimed more than 300 lives since it was discovered in 2012. Bats, rodents and various other mammals host a large number of emerging diseases, too.

Last year, a team led by disease ecologist Peter Daszak, president of the EcoHealth Alliance, a conservation organization headquartered in New York, reported in $m$ Bio the results of an exhaustive survey of all the viruses hosted by a single fruit bat species, the Indian flying fox, which is known to harbor emerging zoonotic pathogens. The

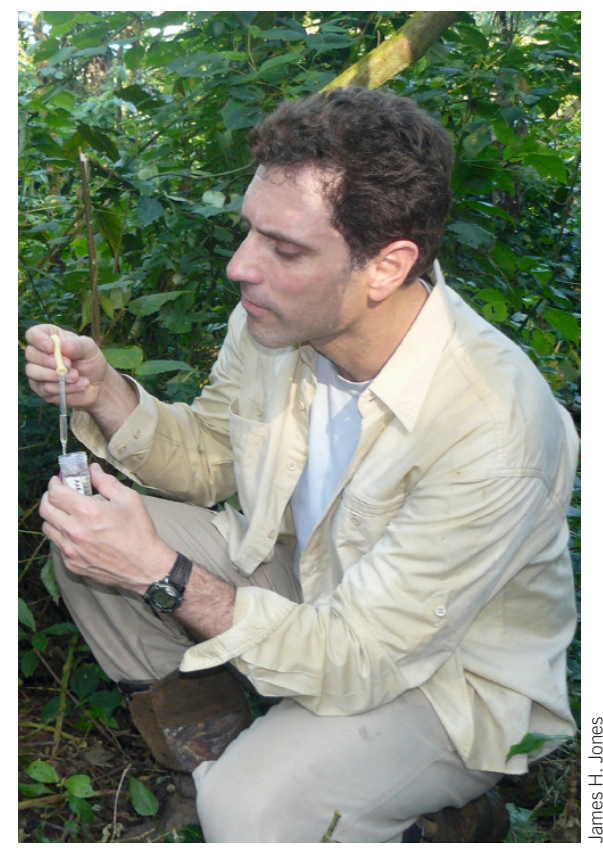

Off the beaten pathway: Tony Goldberg.

researchers-including Ian Lipkin, director of the Center for Infection and Immunity at Columbia University's Mailman School of Public Health in New York, and Jonna Mazet, executive director of the One Health Institute at the University of California-Davisextrapolated those results and came up with a minimum estimate of 320,000 mammalian viruses that await discovery, any of which could conceivably be responsible for the next human pandemic ${ }^{5}$. They called for a targeted surveillance program "to identify agents that pose zoonotic risks before they emerge in people."

Goldberg applauds the strategy put forward in the mBio paper, noting that the authors' estimated price tag of chronicling 


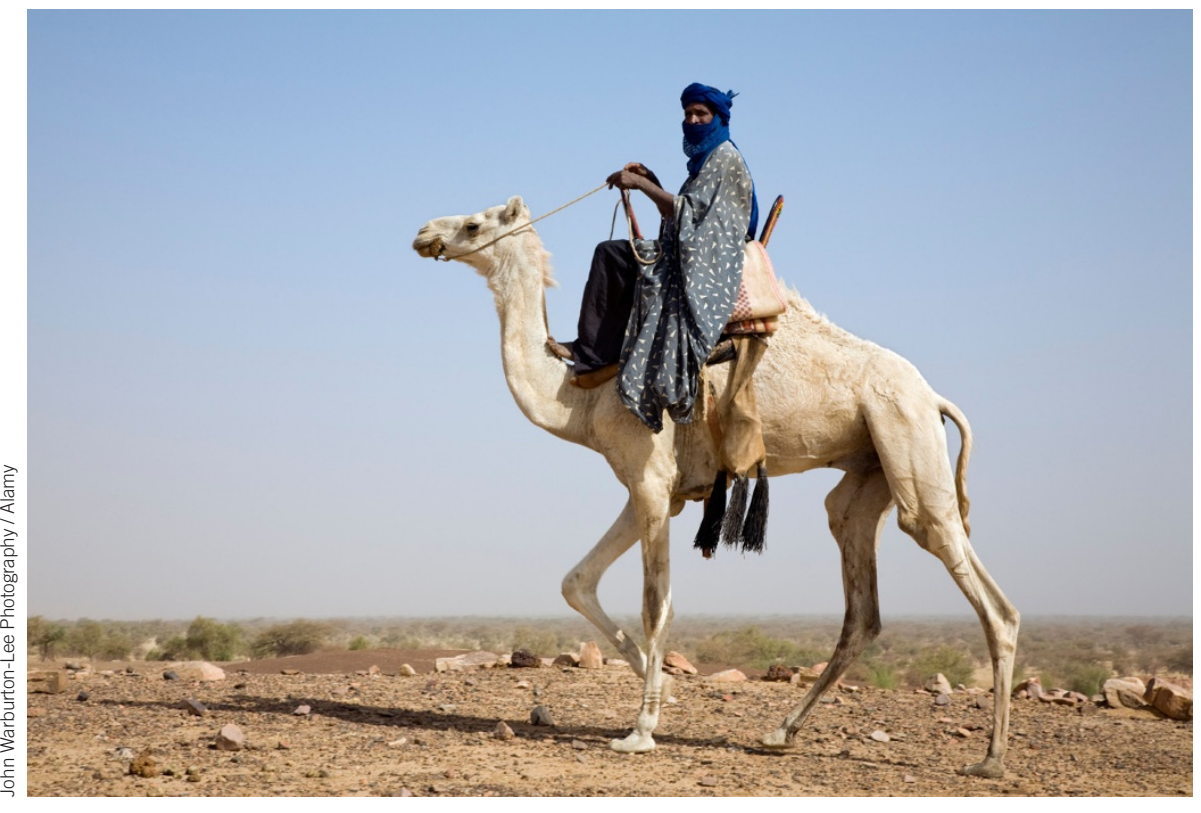

Camel culprit: Camel-to-human transmission responsible for MERS's species jump.

all mammalian viruses $-\$ 6.3$ billion - is still far less than the economic impact of containing even a single pandemic like SARS, which researchers estimate cost the global economy close to $\$ 40$ billion in 2003 alone $^{6}$. But Goldberg emphasizes the need to focus on how the diseases spread: "I'm deeply excited by pathogen discovery-I love it and I do it in my lab-but I think it needs a complementary approach from the ecological and social sciences," Goldberg says. "We should strive to ramp up pathway discovery now that we are in this golden age of pathogen discovery. Together, the two approaches will give us the information we really need."

\section{Provocative proposal}

Jonna Mazet says that she "totally agree[s]" with Goldberg's suggested focus on pathway discovery. "I think it's provocative and hopefully evocative to get things moving." But, she argues, "we've been doing it for five years."

Mazet is the principal investigator of PREDICT, a \$75 million, five-year project established in 2009 by the US Agency for International Development (USAID) that focuses on, among other things, characterizing the human and ecological drivers of disease spillover from animals to people. USAID is now planning a $\$ 100$ million follow-up effort, PREDICT-2; applications to lead the project were due last month.

But whereas PREDICT and other epidemiological efforts have concentrated on characterizing the risks of known zoonotic pathogens and emerging new ones, "my idea is different," Goldberg stresses, because of his unique focus on identifying all transmission pathways that could be potentially used in the future, not just those observed today. "Just as we are being proactive about finding new pathogens before they emerge, so, too, should we be proactive about finding new pathways before they are traversed," Goldberg says.

According to James Holland Jones, a biological anthropologist at Stanford University in California, this will require a heightened focus on the social, cultural and environmental determinants of disease transmission, such as changes in land use that encroach on wildlife habitat or that bring animals into closer proximity with people. "Spillover events are ultimately driven by human behavior," he says, "and we far too often ignore what engineers would call the 'human factors."

"It's a return to first principles," notes Paul Gibbs, a veterinarian and virologist at the University of Florida in Gainesville. Gibbs cites the 160-year-old demonstration by John Snow that contaminated water was the cause of a deadly cholera outbreak in London in 1854, a time before the 'germ theory of disease' had even been developed. "[Snow] didn't even know what the agent was, but he looked at pathways and he looked at how society were moving in London, where they got their water from and, somewhat apocryphally now, he was reported to have taken the pump handle off," Gibbs says. "That is pathway discovery."

Elie Dolgin

1. Hamer, S.A. et al. Am. J. Trop. Med. Hyg. 89, 924-927 (2013).

2. Jones, K.E. et al. Nature 451, 990-993 (2008).

3. Memish, Z.A. et al. Emerg. Infect. Dis. 20, 1012-1015 (2014).

4. Azhar, E.I. et al. N. Engl. J. Med. published online, doi:10.1056/NEJMoa1401505 (4 June 2014).

5. Anthony, S.J. et al. mBio 4, e00598-13 (2013).

6. Lee, J.-W. \& McKibbin, W.J. Estimating the global economic costs of SARS. in Learning from SARS: Preparing for the next Outbreak (eds. Knobler, S. et al.) (The National Academies Press, 2004).

\section{European-African clinical research scheme expands into phase 1}

African countries often host clinical trials that are led by researchers from other continents. But in the last decade, researchers in Africa are increasingly playing a leading role in clinical research, thanks in part to the European and Developing Countries Clinical Trials Partnership (EDCTP), an alliance between 16 European countries that launched in 2003 to collaborate with subSaharan African nations in the development of treatments for HIV/AIDS, tuberculosis and malaria. Since its establishment, EDCTP has provided $€ 212$ million ( $\$ 287$ million) to help fund 100 clinical trials in 30 African countries and to develop the infrastructure and expertise needed to conduct those studies in line with international scientific and ethical standards. Researchers employed by African institutions have led more than $70 \%$ of EDCTP-funded projects.

The current EDCTP program is drawing to a close, but the Netherlands-based organization is gearing up for a second phase of the initiative, known as EDCTP2. So far, 14 European countries have signed up as members of EDCTP2 and have pledged a combined total of $€ 683$ million to the partnership, which is hoped to launch by the end of this year and last until 2023. Of the 16 countries that participated in EDCTP1, Belgium, Greece and Switzerland have not yet joined; Finland was not a member of the program's first phase but has signed 